\title{
3 Research Square

\section{Pathways to Loneliness: A Mediation Analysis Investigating the Social Gradient of Loneliness in Persons With Disabilities in Switzerland}

\section{Hannah Tough ( $\square$ hannah.tough@paraplegie.ch )}

Schweizer Paraplegiker Zentrum https://orcid.org/0000-0002-6213-9150

\section{Mirja Gross-Hemmi}

Swiss Paraplegic Research: Schweizer Paraplegiker Zentrum

Inge Eriks-Hoogland

Swiss Paraplegic Centre: Schweizer Paraplegiker Zentrum

Christine Fekete

Swiss Paraplegic Research: Schweizer Paraplegiker Zentrum

\section{Research}

Keywords: Loneliness, socioeconomic status, spinal cord injury, mediation, psychosocial resources, social isolation, participation

Posted Date: August 19th, 2021

DOI: https://doi.org/10.21203/rs.3.rs-810210/v1

License: (c) (1) This work is licensed under a Creative Commons Attribution 4.0 International License.

Read Full License

Version of Record: A version of this preprint was published at International Journal for Equity in Health on December 1st, 2021. See the published version at https://doi.org/10.1186/s12939-021-01600-5. 


\section{Abstract}

\section{Background}

The experience of loneliness can have drastic consequences for health and quality of life. Given that loneliness is highly prevalent in persons with physical disabilities and that loneliness more profoundly affects persons of low socioeconomic status, more evidence is required in order to understand the mechanisms determining loneliness in this population. The objective of this study is therefore to investigate the potential pathways through which socioeconomic status influences loneliness in persons with spinal cord injury.

Methods

Parallel and serial mediation analysis utilising structural equation models and bias corrected and accelerated confidence intervals were used in order to test the mediation effects of health status, functioning, participation, social support and self-efficacy on the association between socioeconomic status and loneliness in persons with spinal cord injury. A latent construct was created for socioeconomic status with the indicators education, household income, financial hardship, subjective social status and engagement in paid work.

Results

This study found evidence to support the mediating role of psychosocial resources and of secondary health conditions in the association between socioeconomic status and loneliness. The study demonstrated robust associations between socioeconomic status and all mediators, whereby higher socioeconomic status was associated with better health, participation and psychosocial resources. Results also suggested that the serial mediation model explained the interplay between socioeconomic status, mediators on different levels, and loneliness. For example, emotional support and self-efficacy were both positively associated with fewer restrictions to participation $(0.12$ (Cl: $0.05,0.17) ; 0.29$ (Cl: 0.23 , 0.35) respectively), and frequency of participation increased as a result of improved functional independence and fewer secondary health conditions ( 0.31 (Cl: $0.23,0.36) ;-0.18$ (Cl: $-0.24,-0.10)$ respectively).

\section{Conclusions}

This study has emphasized the social gradient of loneliness in persons with spinal cord injury and has identified several potential mediating factors, such as health status and psychosocial resources, in the association between socioeconomic status and loneliness. This population-based evidence suggests potential targets of interventions on the pathway to loneliness, and has identified potential underlying mechanisms, through which socioeconomic status influences loneliness.

\section{Introduction}


The higher prevalence of loneliness in groups with lower socioeconomic status (SES) may contribute to the emergence of health inequalities [1-5]. Not only is loneliness a stressful and negative experience in and of itself, but loneliness has also been identified as a risk factor for poor health behaviours [6], adverse health outcomes [7-9] and mortality.[10, 11] Given its relevance for health, and its potential role in driving health inequalities, preventing loneliness in low SES groups is of high importance. As SES is generally seen as an unmodifiable factor in public health interventions, loneliness could be targeted by identifying and understanding the role of different potentially modifiable mediators on the pathway to loneliness. Therefore, a thorough understanding of mechanisms leading to loneliness is needed for targeted intervention planning, and insights into reasons for the higher prevalence of loneliness in groups with low SES is essential. Although those reasons are currently unclear, there are several theoretical pathways linking SES and loneliness.

Low SES may create the conditions needed for loneliness to thrive. A first approach maintains that low SES acts independently on health, functioning, participation and psychosocial resources, as depicted in the parallel approach (Fig. 1a). For example, low participation can be a direct outcome of low SES in case of lacking financial resources to engage in leisure time activities, or low self-esteem might be a direct consequence of poor SES and related feelings of marginalization. In contrast to this parallel approach, a second approach maintains that poor SES leads to a sequence of poor outcomes that eventually increases the risk of loneliness [12]. More specifically, low SES leads to poorer health status [13], limiting an individual's opportunities for social and labour market participation. Reduced opportunities for social contact due to limitations in participation may subsequently have negative consequences on psychosocial resources, such as reduced self-esteem or self-efficacy, which are closely linked with the concept of loneliness. It is theorized in this approach that SES shapes an individual's psycho-social environment in such a way that persons with low SES have reduced opportunities to engage in social activities, and this has further negative consequences for psycho-social resources. This model, also known as serial mediation assumes a causal chain linking the mediators, with a distinct assumed direction of causal flow [14]. Given the theoretical model which assumes a certain temporal ordering of the mediators used in this study [12], we assume causality to be predominantly unidirectional, this was tested in the serial mediation model (Fig. 1b).

Besides low SES, physical disability may present another risk factor for increased prevalence of loneliness. Loneliness may present an added burden in persons with a physical disability as the prevalence of loneliness is often higher in this population $[15,16]$. Persons coping with physical disability may be exposed to additional risk factors for loneliness, such as restrictions in social participation due to negative societal attitudes, functional limitations and diverse environmental barriers [17]. Persons with physical disabilities may also become emotionally isolated from their existing social circle, especially if they feel that they are no longer understood or if they are living in an intimate relationship whereby one half is providing informal care $[18,19]$. In a recent study of persons affected by a physical disability, subjective social status and experiences of financial hardship were found to have the highest discriminative power in terms of determining loneliness. 
Given that loneliness is highly prevalent in persons with physical disabilities and that evidence on pathways linking SES and loneliness remains largely unexplored in this vulnerable population, the objective of this study is to investigate the potential pathways through which SES influences loneliness in persons with physical disabilities, namely spinal cord injury (SCl). SCl offers an informative case in point, as it often leads to physical disability characterised by varying degrees of functional limitations, depending on the level and completeness of the spinal cord lesion. Parallel and serial mediation analysis will be used in order to uncover where health status, functioning, participation, social support and selfefficacy lie on the path between SES and loneliness, based on the theoretical models presented in Fig. 1a and $1 b$.

\section{Methods}

\section{Participants}

The study utilized cross-sectional data from the Swiss Spinal Cord Injury Cohort Study (SwiSCI), the second population-based SwiSCl community survey [20]. SwiSCl included community-dwelling persons aged over 16 years with traumatic or non-traumatic SCl (e.g. due to degeneration of the spinal column, tumor, vascular problem, or infection) living in Switzerland. We excluded people with congenital conditions leading to $\mathrm{SCl}$, those with neurodegenerative disorders and Guillain-Barré syndrome. Participants were recruited based on records of Swiss Paraplegic Association members (organization representing people with SCl), ParaHelp (specified SCI home care organization) and all four specialized SCl-rehabilitation centers in Switzerland. This resulted in a source population of 4,493 individuals (thereof 3,959 eligible) who were invited to the survey. This study uses data from 1294 individuals, giving a response rate of $32.7 \%$.

\section{Study design}

The second SwiSCl community survey included two questionnaires that were sent to participants with an interval of 4-6 weeks. Data collection was performed between 3/2017 and 3/2018. A mixed-mode data collection design including paper-and-pencil or online questionnaire and face-to-face or telephone interviews was used to achieve optimal response rates. The questionnaires were provided in three official Swiss languages (German, French or Italian) and the English reference questionnaire is available online (https://swisci.ch/en/research-projects-home/study-design/community-survey). Further details on recruitment outcomes, participation rates, and non-response bias in the SwiSCl community survey 2017 can be found elsewhere [20].

\section{Measures}

Loneliness was assessed using three items from the UCLA Three-Item Loneliness Scale (UCLA-SF) which captures subjective feelings of loneliness [21]. Participants were asked to indicate whether they feel that they lacked companionship, feel left out, and feel excluded in everyday life. Response options were on a five-point Likert scale from 0 'not at all' to 4 'completely' and a sum score ranging from 0-12 was built, 
with higher scores representing higher loneliness. The response options were adapted from the original scale, whereby there were three response options. This was as loneliness was assessed as part of a larger battery on psychosocial resources and it was decided to avoid introducing new response scales for different items to reduce participant burden for questionnaire completion. This scale has recently been validated in an $\mathrm{SCl}$ population and showed adequate metric properties [22]. Cronbach's alpha was 0.75 , demonstrating satisfactory internal consistency in our sample.

Socioeconomic status. Education, household income, financial hardship, subjective social status and employment status were used to operationalize SES. Education was assessed according to the International Standard Classification of Education as total years of formal education, combining school and vocational training [23] excluding potential re-training after SCl. Income was measured by net equivalent household income, including information on disposable income weighted by the number of adults and children in the household according to OECD criteria [24]. Financial hardship was measured with a single item asking participants about problems faced due to their financial situation, offering four response options (not applicable, had no influence, made my life a bit more difficult, made my life a lot more difficult) [25]. The MacArthur Scale of Subjective Social Status was used to capture the subjective evaluation of one's position in society, represented by a 10-rung ladder [26]. A single dichotomous variable was used to assess involvement in paid employment (yes/no).

Functioning and health: Functional independence was measured using the self-reported version of the Spinal Cord Independence Measure (SCIM-SR) [27]. This instrument measures independence in performing activities of daily living, such as dressing and feeding oneself, performing transfers out of a wheelchair, and mobility within and outside the house. The sum score comprises the three subscales of self-care, respiratory and bowel management, and mobility. Each item was rated on a scale ranging from 'I need total assistance' to 'I am completely independent'. Rasch transformed scores were used [28]. The scores range from 0 to 100, with higher scores representing higher functional independence. Secondary health conditions were measured using the Spinal Cord Injury Secondary Conditions Scale (SCI-SCS) [29]. A list of 14 secondary health conditions that are commonly diagnosed in people living with $\mathrm{SCl}$ were assessed with information on the presence and impact of health conditions. Self-report of impact is over the past three months and on a 4-point ordinal scale ( 0 'not existing or insignificant'; 1 'mild or infrequent', 2 'moderate or occasional', 3 'severe or chronic'). The health conditions which were assessed were: chronic pain, spasticity, circulatory problems, bladder dysfunction, bowel dysfunction, contractures, urinary tract infections, autonomic dysreflexia, postural hypotension, injury caused by loss of sensation, respiratory problems, pressure injuries, heterotopic ossification, sleep problems. A sum score ranging from 0-42 was built for analysis, with higher scores indicating more secondary conditions.

Participation was measured with two subscales of the Utrecht Scale of Evaluation of RehabilitationParticipation (USER-Participation), namely the frequency and restrictions scales [31]. The frequency scale (11 items) assesses the hours or occasions spent on productive, leisure and social activities and ranges from none at all/never to 36 hours or more/19 times or more. The restrictions scale (11 items) assesses experienced restrictions on vocational, mobility, leisure and social activities due to one's health condition 
and item scores range from 0 (not possible at all) to 3 (no difficulty at all). To assure linear metric properties for use in analysis, Rasch transformed scores were used for the restriction scale. The scores range from 0 to 100 with higher scores representing better participation (higher frequency, less restrictions). A Rasch analysis of the frequency scale (0-100) is not warranted [32], as different productive activities, such as pursuing paid work, doing housework, and volunteering work cannot be performed simultaneously, this renders the scaling of associated frequencies into a single dimension conceptually meaningless.

Psychosocial resources included emotional and tangible social support, and self-efficacy. General Selfefficacy, which describes the general confidence in one's own abilities to overcome difficulties, was assessed using a modified version of the General Self-Efficacy Scale (GSES) consisting of five items. Participants were asked to rate different statements, as for example 'I can find a solution for every problem' or 'I know how to act in an unexpected situation', on a four-point Likert scale ranging from 1 'not true' to 4 'exactly true'. A sum score ranging from 5-20 was built, with higher scores indicating higher selfefficacy [33]. Social support was measured with three items on instrumental and three items on emotional support taken from the Swiss Health Survey [34]. Participants were asked to rate the extent of emotional and tangible support they receive from their partner, family, and friends if needed, on a numeric scale ranging from 0 'not at all' to 10 'very much'. The scale included the option to indicate if a source of support was unavailable (e.g. not having a partner). A mean score ranging from 0 to 10 was calculated from scores of social support sources available, with higher mean score indicating higher level of social support.

\section{Statistical analysis}

First, we describe basic sample characteristics and main variables of interest. Second, we utilized structural equation modelling (SEM) in order to understand the pathways connecting SES with loneliness, while calculating the indirect and direct effects of SES on loneliness with the mediators of functioning and health, participation and psychosocial resources.

As a preparatory step for SEM, we used confirmatory factor analysis to validate the latent SES construct. In a next step, we investigated unadjusted regression coefficients between each of the potential mediators, the latent SES variable and the outcome variable loneliness. If both coefficients (between mediator and SES as well as between SES and loneliness) had a $p$ value $<0.05$, they were included in subsequent models as potential mediators, if not they were dropped from analysis. We also investigated the unadjusted indirect effects over each of the mediators independently and provide standardized coefficients for indirect effects along with bias-corrected Cls.

We then used SEM to test both parallel and serial mediation in order to address the potential ordering of mediators based on the conceptual models presented in Fig. 1a and 1b. Indirect effects estimate the effects of an antecedent variable (SES) on an outcome variable (loneliness) via a mediator or via multiple mediators. Direct effects estimate the effect between SES and loneliness, when controlling for the mediators, and the total effect is the sum of both the indirect and direct effect. 
Bias-corrected and accelerated bootstrapping with 5000 replications with replacements was used to enable the estimation of asymmetrical Cls for the indirect effects in mediation analysis and for multiple mediation models, whereby several mediators are included in one model [35]. Adequate model fit was assessed by a non-significant $\chi^{2}$ test (vulnerable to sample size), a comparative fit index (CFI) $>0.95$, and the root mean square error of approximation (RMSEA) $<0.06$. We compared the model fit indices of the parallel and the serial mediation model to detect which theoretical approach is best supported by the data. We report standardized regression coefficients and 95\% Cls. SEM analysis is conducted on nonimputed data using full information maximum likelihood (FIML) estimation, which adequately accounts for missing data. Proportion of mediated effects will be calculated. All analyses were conducted using STATA Version 16.0 for Windows (College Station, TX, USA) and R (R Core Team (2020)).

\section{Results}

Table 1 profiles the study sample. The majority of participants were male (71\%), mean age was 56.3 years, and on average participants lived for 18.8 years with SCl. Over one third were in paid work, and around one-quarter reported experiencing financial hardship, there was a mean of 14.3 years in formal education and a net household monthly income of $4446 \mathrm{CHF}$. The average score for functional independence was 74.6 on a 0-100 scale and participants reported a mean score of 14.1 for secondary health conditions on a 0-42 scale. On a scale from 0 to 12, participants had a mean score of 2.6 for loneliness, with similar levels of emotional and tangible support, with means of 7.0 and 7.2 respectively on a 0-12 scale. Mean frequency in participation was measured at 29.5 , whereas restrictions was measured at 69.4 on $0-100$ scales.

Table 1: Characteristics of the SwiSCl community survey 2017 population 
Variables (\% missing)

Demographic characteristics

Gender (0)

Male

Female

Age at time of survey in years (0)

\begin{tabular}{ll}
\hline $16-30$ yrs & $54(4.2)$ \\
\hline $31-45$ yrs & $252(19.6)$ \\
\hline $46-60$ yrs & $440(34.3)$ \\
\hline $61-75$ yrs & $428(33.4)$ \\
\hline $76+$ yrs & $109(8.5)$ \\
\hline Education (4.3) & $78(6.4)$ \\
\hline Compulsory schooling $(\leq 9 \mathrm{yrs})$ & $239(19.5)$ \\
\hline Vocational training $(10-12$ yrs $)$ & $607(49.4)$ \\
\hline Secondary education $(13-16$ yrs $)$ & $304(24.8)$ \\
\hline University education $(\geq 17$ yrs $)$ & \\
\hline Employment $(0)$ & $791(61.7)$ \\
\hline Not in paid work & $492(38.3)$ \\
\hline In paid work & $955(76.6)$ \\
\hline Financial hardship $(2.9)$ & $291(23.4)$ \\
\hline No &
\end{tabular}

Net household income (23.4)

Subjective social status (4.7)

SCl characteristics

Years since injury (5.9)

$\leq 5 \mathrm{yrs}$

$166(13.8)$

6-15 yrs
Total $(\mathrm{n}=$

$1,283)$

n (\%)

mean (SD); median (IQR)

$910(70.9)$

$373(29.1)$

56.3 (14.4); 57.0 (21.0)

54 (4.2)

$252(19.6)$

440 (34.3)

$428(33.4)$

$109(8.5)$

$8(6.4)$

(19.5)

(49.4)

(291

4446.6 (1220.7); 3400.0 (1098.2)

5.6 (1.9); 6.0 (3.0) 
Type of SCI (10.8)

Paraplegia/Incomplete

Paraplegia/Complete

Tetraplegia/Incomplete

Tetraplegia/Complete

Cause of $\mathrm{SCl}(1.9)$

Traumatic

Non-traumatic

Functioning \& health

Functional independence (SCIM-SR score) $\quad$ 0-100 (12.3)

Secondary health conditions (SCS-SCI) (25.6)

Participation (USER-P)

Restrictions (5.5)

Frequency (4.5)

Psychosocial resources

Emotional support (1.9)

Tangible support (1.7)

Self-efficacy (GSES) (1.8)

\section{Loneliness}

Loneliness (UCLA-SF) (1.6)

$1-4$
481 (37.5)

326 (25.4)

249 (19.4)

$88(6.9)$

888 (70.5)

$371(29.5)$
Range

0-42
14.1 (7.5); 14.0 (10.0)

74.6 (11.6); 74.2 (10.7)

69.4 (17.9); 68.0 (23.0)

29.5 (14.1); 30.0 (19.3)

$\begin{array}{ll}0-100 & 69.4(17.9) ; 68.0(23.0) \\ 0-100 & 29.5(14.1) ; 30.0(19.3)\end{array}$

7.2 (2.3); 7.7 (3.7)

7.0 (2.3); 7.0 (3.7)

$3.1(0.6) ; 3.0(0.5)$

2.6 (2.6); 2.0 (4.0)

Abbreviations: GSES: General Self-Efficacy Scale; IQR: Interquartile range; SCl: Spinal cord injury; SCIMSR: Spinal Cord Independence Measure for self-report; SCS-SCI: Secondary Conditions Scale for Spinal Cord Injury; SD: Standard deviation; UCLA-SF: UCLA-short form; USER-P: Utrecht Scale of Evaluation of Rehabilitation-Participation

Unadjusted correlations: SES - mediators and mediators - lonelinesS

In unadjusted analysis of associations between SES and mediators, and mediators with loneliness (Table 2 ), all associations were relevant ( $p$ values $<0.05$ ). The indirect effects were largest for the mediators of 
self-efficacy and secondary conditions, which was reflected in the larger proportions of mediated effects. More specifically, nearly $34 \%$ of the effect between SES and loneliness was mediated by self-efficacy, while only around $7 \%$ of the effect between SES and loneliness was mediated by poor frequency of participation.

Table 2: Standardized unadjusted coefficients of associations between socioeconomic status (SES) and mediators, and between mediators and loneliness, including indirect effects of the different SES mediator - Ioneliness paths

\begin{tabular}{|c|c|c|c|c|c|}
\hline SES $\rightarrow>$ Mediator & $\begin{array}{l}\text { Coefficient } \\
(95 \% \mathrm{Cl})\end{array}$ & $\begin{array}{l}\text { Mediator -> } \\
\text { Loneliness }\end{array}$ & $\begin{array}{l}\text { Coefficient } \\
(95 \% \mathrm{Cl})\end{array}$ & $\begin{array}{l}\text { Indirect } \\
\text { effect } \\
\text { Std } \\
\text { estimate } \\
\text { (95\% } \\
\text { bootstrap } \\
\text { Cl) }\end{array}$ & $\begin{array}{l}\text { Proportion } \\
\text { mediated } \\
\text { effect }\end{array}$ \\
\hline
\end{tabular}

Mediators - Psychosocial resources

\begin{tabular}{|c|c|c|c|c|c|}
\hline $\begin{array}{l}\text { SES -> emotional } \\
\text { support }\end{array}$ & $\begin{array}{l}0.46(0.31, \\
0.61)\end{array}$ & $\begin{array}{l}\text { emotional support -> } \\
\text { loneliness }\end{array}$ & $\begin{array}{l}-0.33 \\
(-0.40, \\
-0.27)\end{array}$ & $\begin{array}{l}-0.15 \\
(-0.21, \\
-0.10)\end{array}$ & $21.4 \%$ \\
\hline $\begin{array}{l}\text { SES -> tangible } \\
\text { support }\end{array}$ & $\begin{array}{l}0.41(0.28, \\
0.55)\end{array}$ & $\begin{array}{l}\text { tangible support -> } \\
\text { loneliness }\end{array}$ & $\begin{array}{l}-0.26 \\
(-0.31, \\
-0.20)\end{array}$ & $\begin{array}{l}-0.10 \\
(-0.15, \\
-0.07)\end{array}$ & $14.9 \%$ \\
\hline
\end{tabular}

SES $\rightarrow$ self-

efficacy

$\begin{array}{ll}0.63(0.49, & \text { self-efficacy }-> \\ 0.80) & \text { loneliness }\end{array}$

$-0.39$

$(-0.47$

$-0.24$

$(-0.33$,

$33.9 \%$

$-0.32) \quad-0.17)$

\section{Mediators - Participation}

\begin{tabular}{|c|c|c|c|c|c|}
\hline $\begin{array}{l}\text { SES -> } \\
\text { restrictions }\end{array}$ & $\begin{array}{l}0.71(0.57, \\
0.89)\end{array}$ & $\begin{array}{l}\text { restrictions -> } \\
\text { loneliness }\end{array}$ & $\begin{array}{l}-0.20 \\
(-0.26, \\
-0.15)\end{array}$ & $\begin{array}{l}-0.14 \\
(-0.20, \\
-0.10)\end{array}$ & $21.0 \%$ \\
\hline SES -> frequency & $\begin{array}{l}0.75(0.60 \\
0.94)\end{array}$ & $\begin{array}{l}\text { frequency -> } \\
\text { loneliness }\end{array}$ & $\begin{array}{l}-0.06 \\
(-0.13 \\
0.00)\end{array}$ & $\begin{array}{l}-0.04 \\
(-0.10 \\
0.00)\end{array}$ & $6.9 \%$ \\
\hline
\end{tabular}

Mediators - Functioning and health

\begin{tabular}{|c|c|c|c|c|c|}
\hline $\begin{array}{l}\text { SES -> secondary } \\
\text { conditions }\end{array}$ & $\begin{array}{l}-0.82 \\
(-1.03 \\
-0.62)\end{array}$ & $\begin{array}{l}\text { secondary } \\
\text { conditions -> } \\
\text { loneliness }\end{array}$ & $\begin{array}{l}0.26(0.20, \\
0.33)\end{array}$ & $\begin{array}{l}-0.21 \\
(-0.30 \\
-0.14)\end{array}$ & $29.9 \%$ \\
\hline $\begin{array}{l}\text { SES ->functional } \\
\text { independence }\end{array}$ & $\begin{array}{l}0.53(0.39, \\
0.70)\end{array}$ & $\begin{array}{l}\text { functional } \\
\text { independence -> } \\
\text { loneliness }\end{array}$ & $\begin{array}{l}-0.16 \\
(-0.22 \\
-0.10)\end{array}$ & $\begin{array}{l}-0.09 \\
(-0.13 \\
-0.05)\end{array}$ & $2.5 \%$ \\
\hline
\end{tabular}


Abbreviations: $\mathrm{Cl}$; confidence interval

\section{Parallel mediation model}

Results from the parallel mediation model depicted in Table 3 and Figure 2 suggest that only three variables were responsible for mediation, namely that poorer emotional support, poorer self-efficacy and higher prevalence of secondary health conditions in persons with lower SES mediate the association of SES and loneliness ( $p$ value $<0.05$ ). We found that the indirect effect from SES to loneliness via mediating factors and direct effects from SES to loneliness are comparable in size. More specifically, the proportion of the mediated effect was $50 \%$, with both coefficients for the indirect and direct effect being $-0.60(95 \% \mathrm{Cl}-0.91,-0.34$, and $-1.14,-0.22$, respectively).

Table 3: Standardized indirect, direct and total effects of socioeconomic status on loneliness in the parallel mediation model 
Indirect effects

Std estimate
95\% bootstrap $\mathrm{Cl}$

(Bold $\mathrm{Cl}$ indicate those not crossing 0)

\section{Mediators - Psychosocial resources}

SES -> emotional support -> loneliness

$-0.18$

$-0.29,-0.09$

SES $->$ tangible support $->$ loneliness

$-0.01$

$-0.07,0.07$

SES -> self-efficacy -> Ioneliness

$-0.28$

$-0.43,-0.19$

Mediators - Participation

SES $->$ restrictions $->$ loneliness

$-0.10$

$-0.22,0.04$

SES -> frequency $>>$ loneliness

0.06

$-0.04,0.18$

Mediators - Functioning and health

SES -> secondary conditions -> Ioneliness

$-0.13$

$-0.24,-0.02$

SES -> functional independence -> Ioneliness

0.02

$-0.07,0.12$

\section{Total indirect effect}

Total direct effect

Total effect

Proportion mediated effect
$-0.60$

$-0.60$

$-1.20$

$50.0 \%$

\section{$-0.91,-0.34$}

$-1.14,-0.22$

$-1.72,-0.88$

\section{Model fit}

$$
x^{2}
$$

$757.43(p$

value $<0.001)$

CFI

0.86

RMSEA

0.086

$0.081,0.092$

Abbreviations: Cl: Confidence Interval; $\mathrm{CFI}$ : Comparative Fit Index; RMSEA: Root Mean Square Error of Approximation

Serial mediation model

The majority of hypothesized paths between different variables in the serial mediation model were relevant ( $p$ value $<0.05$; Figure 3 ). However, tangible social support played a relatively unimportant role for 
all tested pathways. The largest indirect effect was seen in the path of SES over functional independence, restrictions in participation and self-efficacy to loneliness $(-0.11(-0.23,-0.06)$, Table 4$)$.

Table 4: Standardized indirect, direct, and total effects of socioeconomic status on loneliness in the serial mediation model

Abbreviations: Cl: Confidence Interval; CFI: Comparative Fit Index; RMSEA: Root Mean Square Error of Approximation

In terms of model fit of the serial and parallel mediation model, both models performed similarly, although the serial model marginally outperforms the parallel model, given its higher CFI and lower RMSEA.

\section{Discussion}

This study aimed to understand the pathways through which SES influences loneliness in a large sample of persons with physical disabilities. In order to do this, parallel and serial mediation models were developed with a number of potential mediator variables selected from the literature and from previous analyses. This study found evidence to support both mediation models, and particularly highlighted the importance of psychosocial resources in the association with loneliness, SES and other mediator variables upstream in the mediating pathway. For example, emotional support and self-efficacy were both positively associated with participation, and participation increased as a result of improved functional independence and fewer secondary health conditions. The parallel mediation model also highlighted the robust associations between SES and all potential mediators in our study, demonstrating the influence of SES on diverse areas of life, from health to psychosocial resources, which ultimately shape the extent of experienced loneliness.

SES demonstrated robust associations with all potential mediators, in both unadjusted as well as the adjusted parallel and serial mediation analysis. This study therefore provides evidence to support the notion that there is a social gradient to many aspects of everyday life, from health status, to participation [36,37], to the availability of psychosocial resources that ultimately contribute to the social gradient in loneliness. Until now this has not been fully explored in the context of SCl, and our study suggests that persons with physical disabilities who are also socially deprived in terms of low SES, suffer from a double burden or an accumulation of risk factors for loneliness. For example, the functional dependence and participation restrictions due to the physical disability may create additional risk factors for loneliness besides the well-known loneliness risk factors associated with low SES.

The importance of psychosocial resources and the qualitative aspects of social relationships for loneliness, and more broadly for wellbeing, has been reported for general populations and populations with $\mathrm{SCl}[12,15,41,42]$. Our study contributes to this evidence by suggesting that although quantitative elements of social relationships, such as frequency and restrictions in participation, do not have direct effects on loneliness in adjusted analysis, they do have indirect effects on loneliness via emotional 
SES-> functional independence -> participation

restrictions -> self-efficacy -> loneliness

SES-> functional independence -> participation

restrictions -> emotional support -> loneliness

SES-> functional independence -> participation restrictions $->$ tangible support $->$ loneliness
$-0.11$
$-0.23,-0.06$

$-0.04$

$-0.08,-0.01$

0.00

$-0.01,0.01$

$-0.05$

$-0.11,-0.02$

SES-> secondary conditions -> participation restrictions ->

$-0.02$

$-0.04,-0.01$

SES-> secondary conditions -> participation restrictions -> emotional support -> Ioneliness

SES-> secondary conditions -> participation restrictions -> $\quad 0.00$

$-0.00,0.00$ tangible support -> loneliness

SES-> functional independence $->$ participation frequency $\quad-\mathbf{0 . 0 2}$ $\rightarrow$ self-efficacy $->$ Ioneliness

SES-> functional independence -> participation frequency $\rightarrow$ emotional support $->$ loneliness

$-0.02$

$-0.05,-0.01$

SES-> functional independence -> participation frequency

0.00

$-0.01,0.00$

$\rightarrow$ tangible support $->$ loneliness

SES-> secondary conditions -> participation frequency -> self-efficacy -> loneliness

$-0.01$

$-0.03,-0.00$

SES-> secondary conditions -> participation frequency $->$

$-0.01$

$-0.04,-0.00$

emotional support -> Ioneliness

SES-> secondary conditions -> participation frequency -> tangible support -> loneliness

0.00

$-0.01,0.00$
Total indirect effect

Total direct effect

Total effect

Proportion mediated effect
$-0.27$

$-1.29$

$-1.57$

$17.4 \%$
$-0.56,-0.16$

$-2.46,-0.60$

$-3.04,-0.80$

\section{Model fit}


support and self-efficacy. This provides evidence for the "filtration model" as proposed by Hawkley et al $[12,43]$. This model suggests that "distal" elements, such as SES and sociodemographic characteristics, shape an individual's social structures, such as their participation in social networks that ultimately influences more "proximal" factors, such as the quality of their social relationships and their psychosocial resources. The conceptual model devised by Hawkley et al was strengthened by our findings in the serial mediation model as the majority of the hypothesized paths between SES, mediators and loneliness were significant. Providing evidence that upstream factors, shaped by the differing opportunities presented to individuals of differing social standing, influence an individual's participation in their social environment $[37,44]$. Perceived level of participation affects the extent to which an individual feels included in their social circle, and the quantity of emotional and tangible resources the social circle can provide [45].

Although this analysis has identified those of low SES to be vulnerable to loneliness, SES cannot generally be directly targeted by public health interventions [38]. Mediation analysis can go further than purely descriptive analysis by identifying potentially modifiable targets of intervention on the pathway to loneliness, and help in understanding underlying mechanisms. Although we see that SES impacts on all of the potential mediators, only secondary health conditions, emotional support and self-efficacy were found to have robust mediation effects in adjusted analysis. The mediating role of secondary health conditions and psychosocial resources in the SES-Ioneliness association has previously been found in the caregivers of persons with SCI [39] and more generally in persons with physical disabilities [40]. This highlights the importance of psychosocial resources, but also hints to the fact that there is a potential interplay between mediating factors on the pathway to loneliness, as mediation results changed after adjustment. This therefore reinforces the need to explore this interplay more thoroughly in the serial mediation model. The question that may now be posed is how this information can be used to tackle loneliness in a population of persons with a physical disability, with the end goal to improve the health and wellbeing As previously stated the social gradient in health is not directly targeted by public health interventions, but rather addressed indirectly through the "health in all policies" directive [46], which may also contain initiatives to reduce participation restrictions for persons with physical disabilities and to strengthen psychosocial resources in this vulnerable population group. Potentially promising interventions for persons with physical disabilities that might ultimately reduce the negative effect of low SES on loneliness include interventions to enhance social support and social skills [47, 48], labour market participation [49], and participation more generally [50].

\section{Strengths and limitations}

SwiSCI is a larger population-based study which provides a well-defined sampling frame and little sampling and response bias [20]. However, the cross-sectional nature of the data precludes inferences about causal relationships. This is especially problematic given that we attempt to compute mediation 
effects, why we restrict our conclusion to the discussion of interplay and associations between the multiple potential mediators, predictor and outcomes. We do however assume that the majority of socioeconomic variables would affect loneliness, and not vice versa. In order to address this issue of uncertain causality, future studies may use longitudinal data once it becomes available. The use of selfreport data is also associated with recall and/or reporting bias as the reporting of health conditions, for example, cannot be validated by clinical data. Finally, variables may also be subject to reporting bias which can lead to spurious associations with loneliness. Loneliness is a broad concept which may overlap with several of the other variables understudy and may be reported, as with other psychological resources, as a shared effect of psychological personal factors. Furthermore, we restricted our analysis to variables suggested by the conceptual model and those available in our dataset. It is plausible that some of the associations exist due to unmeasured confounding or mediation. In light of these strengths and limitations, the main value of the evidence provided by the present study, is to identify vulnerable groups and highlight potential underlying mechanisms that necessitate further research.

\section{Conclusion}

Our findings highlight the vulnerability of persons with low SES to loneliness in persons with SCI. Not only has this study emphasized the social gradient of loneliness, but it has also shown that several of the factors lying on the pathway to loneliness are also strongly linked to SES. This population-based evidence suggests potential targets of interventions on the pathway to loneliness, and has identified potential underlying mechanisms, through which SES influences loneliness.

\section{Abbreviations}

Cl: Confidence interval; CFI: Comparative Fit Index; CHF: Swiss Francs; GSES: General Self-Efficacy Scale; IQR: Interquartile range; OECD: The Organisation for Economic Co-operation and Development ; RMSEA: Root Mean Square Error of Approximation; SCI: Spinal cord injury; SCIM-SR: Spinal Cord Independence Measure for self-report; SCS-SCI: Secondary Conditions Scale for Spinal Cord Injury; SD: Standard deviation; SEM: Structural Equation Modelling; SES: Socioeconomic status; UCLA-SF: UCLA-short form; USER-P: Utrecht Scale of Evaluation of Rehabilitation-Participation

\section{Declarations}

Ethics approval and consent to participate The study protocol and all measurement instruments were approved by the Ethical Committee of Northwest and Central Switzerland (document EKNZ 2014285). Regulations concerning informed consent and data protection were strictly observed and all participants signed an informed consent form. The study was conducted in accordance with the declaration of Helsinki.

Consent for publication Not applicable 
Availability of data and materials The datasets used and/or analysed during the current study are available from the corresponding author on reasonable request

Competing interests None declared

Funding Swiss Paraplegic Foundation, Swiss National Science Foundation, grant number 10001A_182284/1

Authors' contributions HT, MGH, IEH \& CF: Conceptualization; HT \& CF: Formal analysis; HT: Methodology; HT: Writing - original draft; HT, MGH, IEH \& CF: Writing - review \& editing.

Acknowledgements We thank the SwiSCI Steering Committee with its members Xavier Jordan, Fabienne Reynard (Clinique Romande de Réadaptation, Sion); Michael Baumberger, Hans Peter Gmünder (Swiss Paraplegic Center, Nottwil); Armin Curt, Martin Schubert (University Clinic Balgrist, Zürich); Margret HundGeorgiadis, Kerstin Hug (REHAB Basel, Basel); Laurent Prince (Swiss Paraplegic Association, Nottwil); Heidi Hanselmann (Swiss Paraplegic Foundation, Nottwil); Daniel Joggi (Representative of persons with SCI); Mirjana Bosnjakovic (Parahelp, Nottwil); Mirjam Brach, Gerold Stucki (Swiss Paraplegic Research, Nottwil); Armin Gemperli (SwiSCl Coordination Group at Swiss Paraplegic Research, Nottwil).

\section{References}

1. Algren $\mathrm{MH}$, Ekholm O, Nielsen L, Ersbøll AK, Bak CK, Andersen PT. Social isolation, loneliness, socioeconomic status, and health-risk behaviour in deprived neighbourhoods in Denmark: A crosssectional study. SSM-population health 2020; 10:100546.

2. Yang K, Victor C. Age and loneliness in 25 European nations. Ageing and Society 2011; 31:1368.

3. de Jong Gierveld J, Keating N, Fast JE. Determinants of loneliness among older adults in Canada. Canadian Journal on Aging/La Revue canadienne du vieillissement 2015; 34:125-136.

4. de Jong Gierveld J, Tesch-Römer C. Loneliness in old age in Eastern and Western European societies: theoretical perspectives. European Journal of Ageing 2012; 9:285-295.

5. Madsen K, Holstein B, Damsgaard M, Rayce S, Jespersen L, Due P. Trends in social inequality in loneliness among adolescents 1991-2014. Journal of Public Health 2019; 41:e133-e140.

6. Christiansen J, Larsen FB, Lasgaard M. Do stress, health behavior, and sleep mediate the association between loneliness and adverse health conditions among older people? Social Science \& Medicine 2016; 152:80-86.

7. Cacioppo JT, Hawkley LC, Crawford LE, Ernst JM, Burleson MH, Kowalewski RB, Malarkey WB, Van Cauter E, Berntson GG. Loneliness and health: Potential mechanisms. Psychosomatic Medicine 2002; 64:407-417. 
8. Cacioppo JT, Hughes ME, Waite LJ, Hawkley LC, Thisted RA. Loneliness as a specific risk factor for depressive symptoms: cross-sectional and longitudinal analyses. Psychology and aging 2006; 21:140.

9. Hawkley LC, Burleson MH, Berntson GG, Cacioppo JT. Loneliness in everyday life: cardiovascular activity, psychosocial context, and health behaviors. Journal of personality and social psychology 2003; 85:105.

10. Holt-Lunstad J. The potential public health relevance of social isolation and loneliness: Prevalence, epidemiology, and risk factors. Public Policy \& Aging Report 2017; 27:127-130.

11. Holt-Lunstad J, Smith TB, Baker B, Harris T, Stephenson D. Loneliness and Social Isolation as Risk Factors for Mortality: A Meta-Analytic Review. Perspectives on Psychological Science 2015; 10:227-237.

12. Hawkley LC, Hughes ME, Waite LJ, Masi CM, Thisted RA, Cacioppo JT. From social structural factors to perceptions of relationship quality and loneliness: the Chicago health, aging, and social relations study. The Journals of Gerontology Series B: Psychological Sciences and Social Sciences 2008; 63:S375-S384.

13. Marmot M. Social determinants of health inequalities. The lancet 2005; 365:1099-1104.

14. Hayes AF. Introduction to mediation, moderation, and conditional process analysis: A regressionbased approach. Guilford publications; 2017.

15. Tough H, Fekete C, Brinkhof MW, Siegrist J. Vitality and mental health in disability: Associations with social relationships in persons with spinal cord injury and their partners. Disability and health journal 2017; 10:294-302.

16. Emerson E, Fortune N, Llewellyn G, Stancliffe R. Loneliness, social support, social isolation and wellbeing among working age adults with and without disability: Cross-sectional study. Disability and health journal 2021; 14:100965.

17. Fougeyrollas P, Noreau L. Long-term consequences of spinal cord injury on social participation: the occurrence of handicap situations. Disability and Rehabilitation 2000; 22:170-180.

18. UK C. State of Caring Survey 2014 Carers UK; 2014.

19. Korporaal M, van Groenou MIB, van Tilburg TG. Effects of own and spousal disability on loneliness among older adults. Journal of Aging and Health 2008; 20:306-325.

20. Gross-Hemmi MH, Gemperli A, Fekete C, Brach M, Schwegler U, Stucki G. Methodology and study population of the second Swiss national community survey of functioning after spinal cord injury. Spinal Cord 2020:1-10. 
21. Hughes ME, Waite LJ, Hawkley LC, Cacioppo JT. A short scale for measuring loneliness in large surveys results from two population-based studies. Research on aging 2004; 26:655-672.

22. Robinson-Whelen S, Taylor HB, Feltz M, Whelen M. Loneliness among people with spinal cord injury: exploring the psychometric properties of the 3-item loneliness scale. Archives of physical medicine and rehabilitation 2016; 97:1728-1734.

23. UNESCO. International standard classification of education (ISCED). Paris; 1997.

24. Hagenaars AK, de Vos K, Zaidi MA. Poverty statistics in the late 1980s: Research based on micordata. (Communities OfOPotE ed. Luxembourg; 1994.

25. Ballert CS, Post MW, Brinkhof MW, Reinhardt JD, Group SS. Psychometric properties of the Nottwil Environmental Factors Inventory short form. Archives of physical medicine and rehabilitation 2015; 96:233-240.

26. Adler N, Stewart J. The MacArthur Scale of Subjective Social Status. 2007.

27. Fekete $\mathrm{C}$, Eriks-Hoogland I, Baumberger M, Catz A, Itzkovich M, Lüthi H, Post M, Von Elm E, Wyss A, Brinkhof M. Development and validation of a self-report version of the Spinal Cord Independence Measure (SCIM III). Spinal Cord 2013; 51:40-47.

28. Prodinger B, Ballert CS, Brinkhof MW, Tennant A, Post MW. Metric properties of the Spinal Cord Independence Measure-Self Report in a community survey. Journal of Rehabilitation Medicine 2016; 48:149-164.

29. Kalpakjian CZ, Scelza WM, Forchheimer MB, Toussaint LL. Preliminary reliability and validity of a spinal cord injury secondary conditions scale. The journal of spinal cord medicine 2007; 30:131-139.

30. Brinkhof MW, Al-Khodairy A, Eriks-Hoogland I, Fekete C, Hinrichs T, Hund-Georgiadis M, Meier S, Scheel-Sailer A, Schubert M, Reinhardt JD. Health conditions in people with spinal cord injury: contemporary evidence from a population-based community survey in Switzerland. Journal of rehabilitation medicine 2016; 48:197-209.

31. Post MW, van der Zee CH, Hennink J, Schafrat CG, Visser-Meily JM, van Berlekom SB. Validity of the utrecht scale for evaluation of rehabilitation-participation. Disability and rehabilitation 2012; 34:478485 .

32. Mader L, Post MW, Ballert CS, Michel G, Stucki G, Brinkhof MW. Metric properties of the Utrecht Scale for Evaluation of Rehabilitation-Participation (USER-Participation) in persons with spinal cord injury living in Switzerland. Journal of Rehabilitation Medicine 2016; 48:165-174.

33. Schwarzer R, Jerusalem M. Generalized self-efficacy scale. Measures in health psychology: A user's portfolio Causal and control beliefs 1995; 1:35-37. 
34. al Be. Social relationship correlates of major depressive disorder and depressive symptoms in Switzerland: nationally representative cross sectional study. BMC Public Health 2014; 14.

35. Preacher KJ, Hayes AF. Asymptotic and resampling strategies for assessing and comparing indirect effects in multiple mediator models. Behavior research methods 2008; 40:879-891.

36. Niedzwiedz CL, Richardson EA, Tunstall H, Shortt NK, Mitchell RJ, Pearce JR. The relationship between wealth and loneliness among older people across Europe: Is social participation protective? Preventive medicine 2016; 91:24-31.

37. Lindström M, Hanson BS, Östergren P-O. Socioeconomic differences in leisure-time physical activity: the role of social participation and social capital in shaping health related behaviour. Social science \& medicine $2001 ; 52: 441-451$.

38. Dow WH, Schoeni RF, Adler NE, Stewart J. Evaluating the evidence base: Policies and interventions to address socioeconomic status gradients in health a. 2010.

39. Tough H, Brinkhof MW, Siegrist J, Fekete C. Social inequalities in the burden of care: a dyadic analysis in the caregiving partners of persons with a physical disability. International journal for equity in health 2020; 19:1-12.

40. Xie H, Peng W, Yang Y, Zhang D, Sun Y, Wu M, Zhang J, Jia J, Su Y. Social support as a mediator of physical disability and depressive symptoms in Chinese elderly. Archives of psychiatric nursing 2018; 32:256-262.

41. Ellwardt L, Aartsen M, Deeg D, Steverink N. Does loneliness mediate the relation between social support and cognitive functioning in later life? Social science \& medicine 2013; 98:116-124.

42. Moorman SM. Dyadic perspectives on marital quality and loneliness in later life. Journal of Social and Personal Relationships 2016; 33:600-618.

43. Berkman LF, Glass T, Brissette I, Seeman TE. From social integration to health: Durkheim in the new millenium Social Science \& Medicine 2000; 51:843-857.

44. Ashida T, Kondo N, Kondo K. Social participation and the onset of functional disability by socioeconomic status and activity type: The JAGES cohort study. Preventive medicine 2016; 89:121-128.

45. Li C, Jiang S, Li N, Zhang Q. Influence of social participation on life satisfaction and depression among Chinese elderly: Social support as a mediator. Journal of community psychology $2018 ; 46: 345-$ 355 .

46. Puska P. Health in all policies. The European Journal of Public Health 2007; 17:328-328. 
47. Masi CM, Chen H-Y, Hawkley LC, Cacioppo JT. A meta-analysis of interventions to reduce loneliness. Personality and Social Psychology Review 2011; 15:219-266.

48. Sherman J, DeVinney D, Sperling K. Social Support and Adjustment After Spinal Cord Injury: Influence of Past Peer-Mentoring Experiences and Current Live-In Partner. Rehabilitation psychology 2004; 49:140.

49. Schönherr M, Groothoff J, Mulder G, Schoppen T, Eisma W. Vocational reintegration following spinal cord injury: expectations, participation and interventions. Spinal cord 2004; 42:177-184.

50. Gómara-Toldrà N, Sliwinski M, Dijkers MP. Physical therapy after spinal cord injury: a systematic review of treatments focused on participation. The journal of spinal cord medicine 2014; 37:371-379.

\section{Figures}



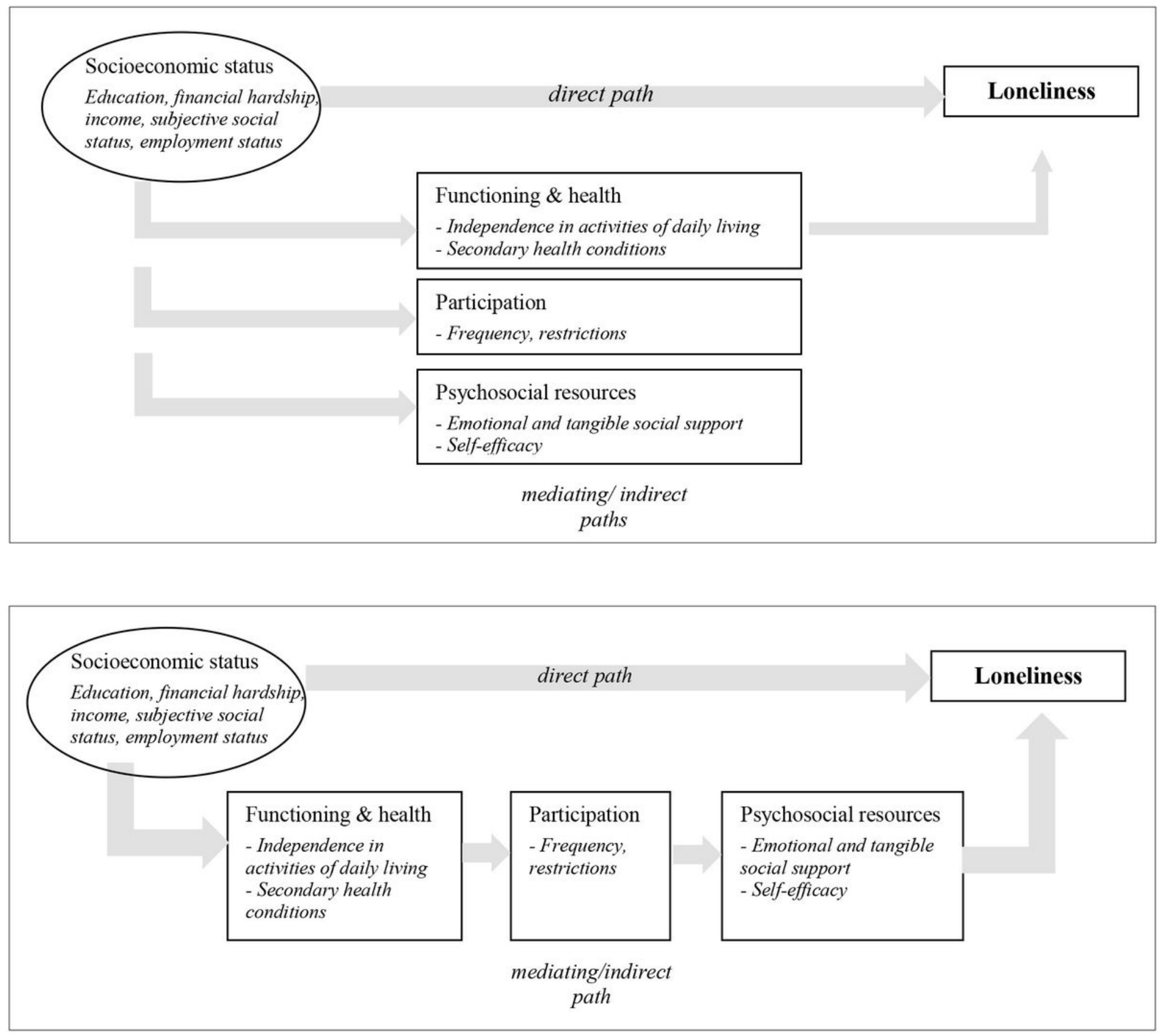

\section{Figure 1}

a: Parallel approach linking socioeconomic status and loneliness. b: Serial approach linking socioeconomic status and loneliness. 


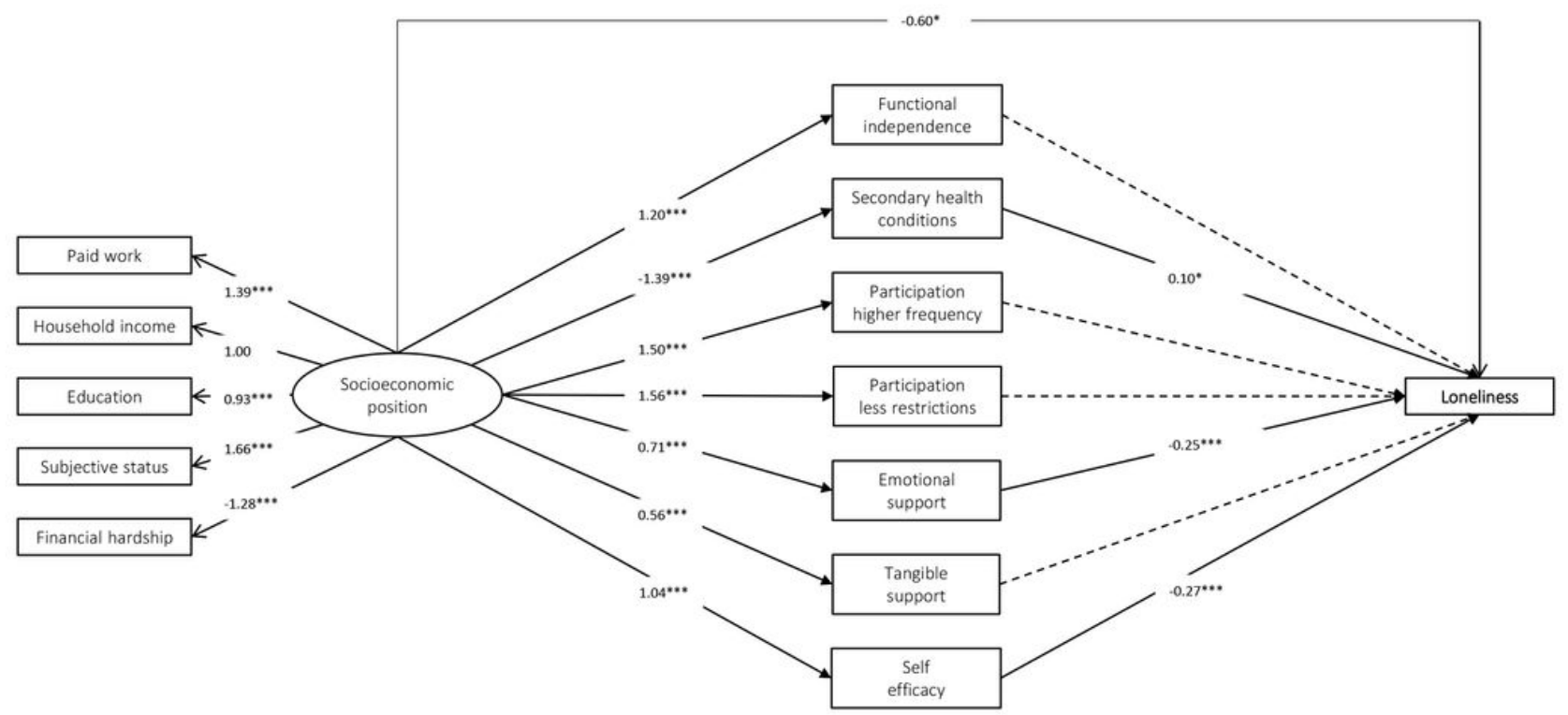

Figure 2

Parallel mediation model on the association between socioeconomic status and loneliness. Numbers indicate path coefficients. Dashed lines indicate non-significant paths, continuous lines indicate significant paths $\left({ }^{*} \mathrm{p}<0.05 ;{ }^{* *} \mathrm{p}<0.01 ;{ }^{* \star *} \mathrm{p}<0.001\right)$ 


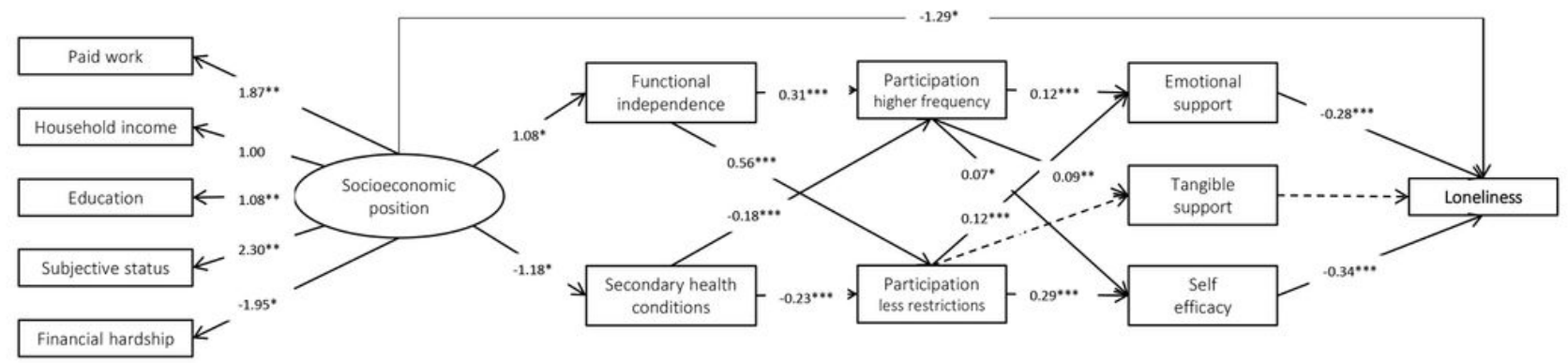

\section{Figure 3}

Serial mediation model on the association between socioeconomic status and loneliness including the mediators functioning and health, participation and psychosocial resources. Numbers indicate path coefficients. Dashed lines indicate non-significant paths, continuous lines indicate significant paths $\left({ }^{\star} \mathrm{p}<0.05 ;{ }^{* \star} \mathrm{p}<0.01 ;{ }^{* \star *} \mathrm{p}<0.001\right)$ 